\title{
The Longer we Dwell on our Misfortunes, the Greater is their Power to Harm us.
}

Arig Mussa *, and Ciaran F. Healy.

National University of Ireland, Galway (NUIG), Ireland.

*Corresponding Author: Arig Mussa, National University of Ireland, Galway (NUIG), Ireland. Received date: December 30, 2020; Accepted date: January 17, 2021; Published date: January $20,2021$.

Citation: Arig Mussa, and Ciaran F. Healy, The longer we dwell on our misfortunes, the greater is their power to harm us, J. New Medical Innovations and Research, 2(1): DOI: 10.31579/jnmir.2021/003.

Copyright: (c) 2021 Arig Mussa. This is an open-access article distributed under the terms of The Creative Commons Attribution License, which permits unrestricted use, distribution, and reproduction in any medium, provided the original author and source are credited.

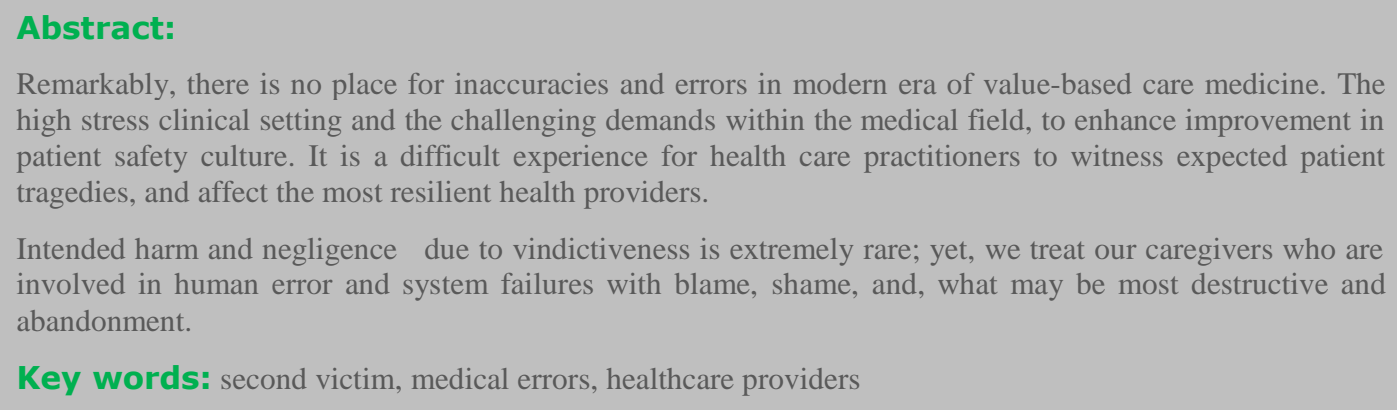

\section{Introduction:}

Remarkably, there is no place for inaccuracies and errors in modern era of value-based care medicine. The high stress clinical setting and the challenging demands within the medical field, to enhance improvement in patient safety culture. It is a difficult experience for health care practitioners to witness expected patient tragedies, and affect the most resilient health providers [1-3].

Intended harm and negligence due to vindictiveness is extremely rare; yet, we treat our caregivers who are involved in human error and system failures with blame, shame, and, what may be most destructive and abandonment [4].

During the mid-1980s [1, 5], literature addressed the need for institutional support for health providers, who experienced intense feelings of inadequacy, incompetence, or guilt after a medical error [1,6]. Signs and symptoms of the emotional aftershock, inevitably, persist for a fluctuating period of time; varying from several days, too many weeks and could even be prolonged further $[1,7,8]$. Never the less, the psychological impact may be devastating and so grave to bring to an end all the future of professional activity [9].

Adverse events can lead to two victims within health care settings. The first victim is the patient and family and the second victim is the involved practitioner [7].

In 2000 , the term "second victim" was seminally created by $\mathrm{Wu}$, in identification of the profound and long-lasting impact medical errors and adverse events may have on medical practitioners as a consequence of preventable medical errors $[1,6,7,10,11]$. Although patients are the first and foremost and apparent victims of medical errors, doctors are deeply injured by the same error: they are the second victims of errors who will also become a patient of the organization (a patient who will over and over again be ignored and suffered in silence) $[5,6,8,11]$. Second victim incidents can impact the welfare of the relevant healthcare providers and can place patient wellbeing in jeopardy $[5,6,12]$. Nevertheless promptly, emotional support is needed to be addressed so as to prevent long term career sequelae that could interfere with their professional careers [2]. However, Burlison et al, revealed that second victim experiences directed clinician and nurses to increase their vigilance to patient safety and enhance co-worker relationship [1].

Despite the fact second victims have been fairly described for several years, in 2009, a formal definition was:

(A second victim is a health care provider involved in an unanticipated adverse patient event, medical error and/or a patientrelated injury who become victimized in the sense that the provider is traumatized by the event. Frequently, second victims feel personally responsible for the unexpected patient outcomes and feel as though they have failed their patients, second-guessing their clinical skills and knowledge base) adapted definition from Scott [5].

The enhancement of our health system depends on the fundamental rights of our patients to safe, high quality, value-based, consistent and patientcentred care [9]. Patient safety is critical and most important as a primary and utmost ambition of medicine [11]. However, we also have to ensure that our health care provisional ( HCPs) are aware of post-event policies and guidelines to govern the handling of the adverse events as well as the expectation to be treated with respect, supported by their colleagues, and not to be abandoned by the health care organization [5,6]. Support initiatives for second victims necessitate to be established and widely communicated so that health care personnel are aware of available resources, amenable to accepting help, and guidance [1,5].Essentially, all 
HCP should contribute in the process of learning form error in just and fair culture [5,6,11].

In 2009, University of Missouri Health Care (MUHC) deployed a second victim emotional support infrastructure. This infrastructure, known as the for YOU Team, is a first-of-its-kind evidence-based second victim intervention that represents immediate emotional and social support $[3,6]$. However, this study discloses that the influence of the second victim experience and the provision of support to individual clinicians may extend beyond the clinicians themselves, penetrating the working environment at both the unit and overall facility levels $[3,6]$.

Burlison et al, develops a survey instrument, the Second Victim Experience and Support Tool (SVEST) that can facilitate healthcare organizations to implement the performance of support resources for second victims [1].

Precise evaluation of the depth and breadth of opportunities for improvement is a fundamental component in the cycle of organizational learning. Healthcare organizations can use the SVEST to assess the quality of existing resources as well as second victim experiences of their staff [1]. Additionally, it can provide the leaders of healthcare organisations with relevant details on second victim-related support resources that would benefit their staff. The SVEST can be administered before and after implementing new second victim resources to measure perceptions of effectiveness [1].

Grissinger, revealed five human rights of second victims (TRUST): (Treatment that is just, Respect, Understanding and Compassionate, Supportive Care, and Transparency and the opportunity to contribute to learning) $[4,11]$.

In 2011, intense emotional recounts brought tears to eyes following the death of Kimberly Hiatt (a nurse) committed suicide following her fatal medication error [11]. Regrettably, no way could we minimize the catastrophe of the critically ill infant's death in this particular event. However, the death of Kimberly Hiatt is no less dreadful. Perhaps, we can only grieve since it's too late to help Kimberly, but her story can serve as an inspiration for one of the most mandatory changes in health caresupport of the second victims of human errors, our injured healers.

\section{Conclusion:}

The second victim experience can be tremendously unpleasant and can have a considerable impact on clinicians, colleagues and patients. When an unfortunate event occurs, it is vital that support networks are implemented to protect and support both patients and the impacted healthcare providers [7].

\section{References:}

1. Jonathan D. Burlison, S. D. S., Emily K. Browne, Sierra G. Thompson, James M. Hoffman (2017). The second victim experience and support tool (SVEST):Validation of an organizational resource for assessing secondvictim effects and the quality of support resources. J Patient Saf.; Vol. 13(2): 93102.

2. Scott, S. D. (2014). Second victim exposure and resultant impact on patient safety perceptions (Doctoral dissertation, University of Missouri--Columbia).

3. Susan D. Scott. Laura E. Hirschinger, Karen R. Cox, Myra; McCoig; Kristin Hahn-Cover, Kerri M. Epperly, et. all (2010). Caring for our own: deploying a systemwide second victim rapid response team. Jt Comm J Qual Patient Saf; Vol. 36(5): 233-240.

4. Denham, C. R. (2007), "TRUST: The 5 Rights of the Second Victim.". J Patient Saf, June 2007; Vol. 3: 107-119.

5. Scott, S. D., Hirschinger, L. E., Cox, K. R., McCoig, M., Brandt, J., \& Hall, L. W. (2009), The natural history of recovery for the healthcare provider "second victim" after adverse patient events Qual Saf Health Care Vol 18; 325-330.

6. Scott, S. D. (2015), Second Victim Support: Implications for Patient Safety Attitudes and Perceptions Clarke, M., Ed. Patient Safety and Quality HealthCare.

7. Deborah Seys, Eva Van Gerven, Arthur Vleugels, Martin Euwema, Massimiliano Panella, et. all (2012), Health Care Professionals as Second Victims after Adverse Events: A Systematic Review. Evaluation \& the Health Professions; vol. 36, 2 : pp. 135-162.

8. Wu, A. W. (2000), "Medical error: the second victim. The doctor who makes the mistake needs help too.". BMJ (Clinical research ed.), Vol. 320,7237: 726-727.

9. Bruno, (2017), Key Principles in Quality and Safety in Radiology. American Journal of Roentgenology. Vol. 208(3):W1-W9.

10. Tumelty, (2018), The Second Victim: A Contested Term? J Patient Saf.

11. M., G. (2014), Too many abandon the "second victims" of medical errors. P\&T, ; Vol. 39(9):591-592.

12. Quillivan RR, B. J., Browne EK, Scott SD, Hoffman JM. (2016), Patient Safety Culture and the Second Victim Phenomenon: Connecting Culture to Staff Distress in Nurses. . Jt Comm J Qual Patient Saf ;42(8):377-386.

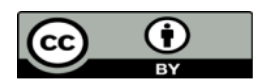

This work is licensed under Creative Commons Attribution 4.0 License

To Submit Your Article Click Here: Submit Manuscript

DOI: 10.31579/jnmir.2021/003.
Ready to submit your research? Choose Auctores and benefit from:

* fast, convenient online submission
rigorous peer review by experienced research in your field
*apid publication on acceptance
* authors retain copyrights
* unique DOI for all articles
immediate, unrestricted online access

At Auctores, research is always in progress.

Learn more www.auctoresonline.org/journals/new-medical-innovationsand-research 